\title{
FOSFATOS DE CÁLCIO DE INTERESSE BIOLÓGICO: IMPORTÂNCIA COMO BIOMATERIAIS, PROPRIEDADES E MÉTODOS DE OBTENÇÃO DE RECOBRIMENTOS
}

\author{
Antonio Carlos Guastaldi* e Anahi Herrera Aparecida \\ Departamento de Físico-Química, Instituto de Química, Universidade Estadual Paulista, Rua Prof. Francisco Degni, s/n, \\ 14800-900 Araraquara - SP, Brasil
}

Recebido em 12/8/09; aceito em 1/2/10; publicado na web em 5/5/10

\begin{abstract}
CALCIUM PHOSPHATES OF BIOLOGICAL INTEREST: IMPORTANCE AS BIOMATERIALS, PROPERTIES AND METHODS FOR COATINGS OBTAINING. For decades the Hydroxyapatite (HA) was only bioceramic of calcium phosphate system used for bone replacement and regeneration, due to its similarity to the mineral phase of bones and teeth. Because its slow degradation, other calcium phosphate classified as biodegradable started to awaken interest, such as: amorphous calcium phosphate (ACP), octacalcium phosphate (OCP) and tricalcium phosphate (TCP). This work presents the evolution of the use of other calcium phosphates due to their better solubility than the HA, comparing their main physical-chemical and biological properties. Are also presented the main methods used to obtain bioceramic coatings on metal and polymer surfaces.
\end{abstract}

Keywords: biomaterials; calcium phosphates; bioceramics.

\section{INTRODUÇÃO}

O aumento da expectativa de vida da população mundial tornou doenças relacionadas à estrutura óssea um problema de saúde público, sendo suficiente para que a ONU declarasse, em 30/11/1999, a década de 2000 a 2010 como "A década do osso e das juntas". Um dos setores de maior demanda é o de ortopedia, onde diversos autores alertam para a premência na priorização de políticas públicas voltadas aos problemas osteoarticulares e para a necessidade de desenvolvimento de novos materiais e aprimoramento dos dispositivos já disponíveis para a correção de problemas existentes e possibilitar melhor qualidade de vida aos pacientes. ${ }^{1}$

Materiais utilizados para a substituição e regeneração da estrutura óssea enquadram-se na classe de materiais denominados biomateriais. Estes materiais devem apresentar um conjunto de propriedades físicas, químicas e biológicas que permitam desempenhar a função desejada, além de estimular uma resposta adequada dos tecidos vivos. ${ }^{2}$

De acordo com a resposta induzida ao meio biológico, os biomateriais podem ser classificados em bioinertes, biotoleráveis e bioativos. A resposta induzida pelos materiais bioinertes e biotoleráveis, em relação ao tecido ósseo, é a encapsulação do implante por uma camada de tecido fibroso não aderente, que impossibilita a interação direta entre implante e tecido, podendo levar à instabilidade e falha. Os materiais bioativos são capazes de interagir intimamente com o tecido vivo sem a intervenção de tecido fibroso. Uma resposta biológica específica na interface com o tecido vivo possibilita a formação de uma ligação química entre o material e o próprio tecido vivo, também chamada por bioadesão. ${ }^{3}$ A Figura 1 apresenta o comportamento das classes de biomateriais quando implantados em defeitos ósseos.

\section{IMPORTÂNCIA DOS FOSFATOS DE CÁLCIO COMO BIOMATERIAIS}

Os ossos e dentes de todos os vertebrados são compósitos naturais formados por moléculas de colágeno ligadas em cadeias lineares arranjadas em fibras. Entre estas moléculas há pequenos compartimentos intersticiais regularmente espaçados, onde estão

\footnotetext{
*e-mail: guastald@iq.unesp.br
}

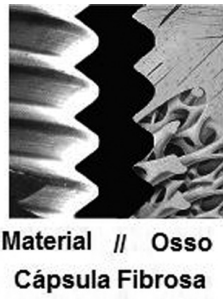

(a)

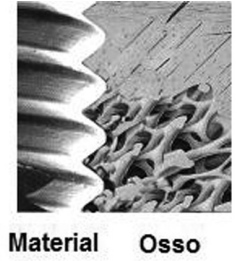

(b)
Figura 1. Comportamento biológico dos biomateriais: a) bioinertes e biotoleráveis e b) bioativos

presentes nanocristais de um sólido inorgânico, que representa cerca de $65 \%$ da massa total do osso, Figura 2. Em 1926, De Jong observou a semelhança entre os padrões de difração de raios-X destes nanocristais inorgânicos e de um composto de fosfato de cálcio. Apesar do componente mineral do tecido ósseo não apresentar composição definida e mostrar variações entre os estágios de maturação e envelhecimento, sua estrutura cristalina e razão $\mathrm{Ca} / \mathrm{P}$ assemelhavam-se às da $\mathrm{HA}$, apresentando ainda a presença de íons $\mathrm{Na}^{+}, \mathrm{Mg}^{2+} \mathrm{e} \mathrm{CO}_{3}{ }^{2-} \mathrm{e}$ em menor quantidade $\mathrm{K}^{+}, \mathrm{F}^{-}$e $\mathrm{Cl}^{-}$, podendo ser caracterizada como uma hidroxiapatita carbonatada de composição representada por:

$\mathrm{Ca}_{8,3} \square_{1,7}\left(\mathrm{PO}_{4}\right)_{4,3}\left(\mathrm{CO}_{3}\right)\left(\mathrm{HPO}_{4}\right)_{0,7}\left(\mathrm{OH}, \mathrm{CO}_{3}\right)_{0,3} \square_{1,7}$

onde $\square$ representa as possíveis substituições catiônicas. Desde então, vários estudos foram conduzidos para testar os efeitos de diferentes fosfatos de cálcio em contato com o tecido ósseo vivo. ${ }^{4}$

A deposição do fosfato de cálcio nas moléculas de colágeno ocorre por um processo de biomineralização controlado envolvendo mais de 200 diferentes proteínas, que atuam como inibidores e nucleares para o crescimento epitaxial e ancoragem ao colágeno. Por outro lado, a cristalização do fosfato de cálcio presente no tecido ósseo envolve a formação cineticamente controlada de produtos intermediários metaestáveis. Dentro de condições in vitro, é observada a transformação de um fosfato de cálcio amorfo a fosfato octacálcico (OCP), o qual se converte ao fosfato de cálcio com composição semelhante a HA. ${ }^{4}$

Os fosfatos de cálcio apresentam-se hoje como os principais materiais estudados e empregados como biomaterial para a reposição 


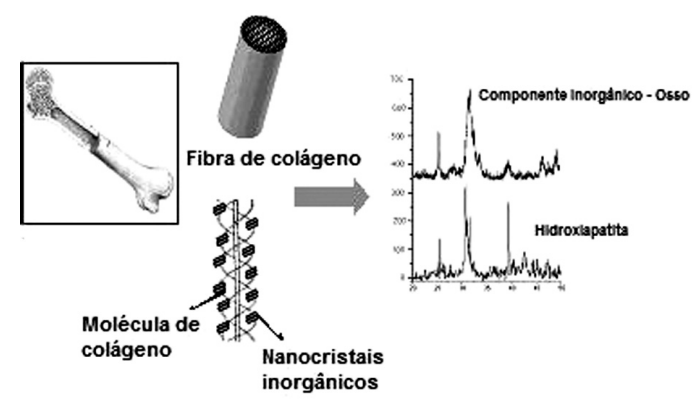

Figura 2. Arranjo da HA e do colágeno no tecido ósseo e semelhança dos padrões de difração de raios $X$ do componente inorgânico do tecido ósseo e da HA

e regeneração do tecido ósseo, pois apresentam como principais características: semelhança com a fase mineral de ossos, dentes e tecidos calcificados; excelente biocompatibilidade; bioatividade; ausência de toxicidade; taxas de degradação variáveis; osteocondutividade (indicam o caminho para o crescimento ósseo, fazendo que ocorra sobre a superfície ou através dos poros).

Devido à sua similaridade química e estrutural com a fase mineral presente em ossos e dentes, durantes os últimos 20 anos a HA foi o principal material de escolha para a reposição do tecido ósseo em aplicações médicas, ortopédicas e odontológicas, como recobrimento ou materiais densos. ${ }^{5}$ Trata-se de um material que apresenta ausência de toxicidade local e sistêmica, ausência de respostas inflamatórias e aparente habilidade em se ligar ao tecido hospedeiro. ${ }^{2,6}$ Contudo, apesar de suas propriedades biológicas promissoras, seu baixo índice de bioatividade ( $\mathrm{Ib}$ ) e sua lenta taxa de degradação passaram a se apresentar como fatores limitantes para sua utilização. Neste cenário, surge o interesse no conhecimento das propriedades e comportamento biológico de outros fosfatos de cálcio para o seu emprego como biomateriais para a reposição óssea. ${ }^{7}$ A Tabela 1 relaciona diversos fosfatos de cálcio e suas ocorrências em sistemas biológicos.

Tabela 1. Ocorrências de fosfatos de cálcio em sistemas biológicos

\begin{tabular}{|c|c|}
\hline Fosfato de cálcio & Ocorrências \\
\hline Hidroxiapatita (HA) & $\begin{array}{c}\text { Esmalte, dentina, osso, cálculo dentário e } \\
\text { urinário. }\end{array}$ \\
\hline Fosfato de cálcio amorfo (ACP) & Cálculo dentário e urinário. \\
\hline Fosfato octacálcico (OCP) & Cálculo dentário e urinário. \\
\hline $\begin{array}{l}\text { Mono-hidrogênio fosfato de } \\
\text { cálcio di-hidratado (DCPD) }\end{array}$ & Cálculo dentário, ossos decompostos. \\
\hline Fosfato tricálcico (TCP) & $\begin{array}{l}\text { Cálculo dentário e urinário, pedras salivares, } \\
\text { cáries dentárias. Calcificação de tecido mole. }\end{array}$ \\
\hline $\begin{array}{l}\text { Pirofosfato de cálcio } \\
\text { di-hidratado (CPPD) }\end{array}$ & Depósitos de pseudo-gotas em fluidos. \\
\hline
\end{tabular}

A bioatividade dos materiais bioativos pode ser quantificada pelo índice de bioatividade (Ib), que é descrito como o tempo necessário para ocorrer $50 \%$ de ligação interfacial entre um biomaterial e o tecido ósseo. Materiais que apresentam índice de bioatividade maior que 8 são classificados como de classe A e são osteoprodutores, ou seja, promovem uma resposta intracelular e extracelular que permite a colonização de sua superfície por células tronco livres no ambiente defeituoso. Materiais com índice entre 0 e 8 são classificados como de classe $\mathrm{B}$, exibindo somente osteocondutividade, ou seja, propiciam o crescimento ósseo ao longo de sua superfície. Na Tabela 2 são apresentados exemplos de materiais de cada classe de bioatividade, bem como o comportamento frente aos tecidos moles e ao osso, onde se pode observar o baixo $\mathrm{I}_{\mathrm{b}}$ da HA, sendo superior apenas ao da alumina, a qual é classificada como um biomaterial bioinerte.
Tabela 2. Índice de bioatividade $\left(\mathrm{I}_{\mathrm{b}}\right)$ de diferentes biomateriais

\begin{tabular}{lcccc}
\hline Biomaterial & Ib & $\begin{array}{c}\text { Classe de } \\
\text { bioatividade }\end{array}$ & $\begin{array}{c}\text { Ligação } \\
\text { com o osso }\end{array}$ & $\begin{array}{c}\text { Ligação com } \\
\text { tecido mole }\end{array}$ \\
\hline Vidro bioativo (4555) & 12,5 & $\mathrm{~A}$ & Sim & Sim \\
Vidro bioativo (5254) & 10,5 & $\mathrm{~A}$ & Sim & Sim \\
Cerâmica bioativa (AW) & 6,0 & $\mathrm{~B}$ & Sim & Não \\
Hidroxiapatita (HA) & 3,1 & $\mathrm{~B}$ & Sim & Não \\
Alumina & 0 & - & Não & Não \\
\hline
\end{tabular}

\section{CLASSIFICAÇÃO DOS FOSFATOS DE CÁLCIO}

Uma forma conveniente de classificar os fosfatos de cálcio é através da razão molar entre os átomos de cálcio e fósforo (razão $\mathrm{Ca} / \mathrm{P}$ ), a qual varia de 0,5 a 2,0 , conforme mostra a Tabela $3 .^{8}$

Tabela 3. Razão Ca/P dos fosfatos de cálcio

\begin{tabular}{lcc}
\hline Fosfato de cálcio & Fórmula química & $\mathrm{Ca} / \mathrm{P}$ \\
\hline Fosfato tetracálcico (TeCP) & $\left.\mathrm{Ca}_{4} \mathrm{O}_{(\mathrm{PO}}\right)_{2}$ & 2,0 \\
Hidroxiapatita (HA) & $\mathrm{Ca}_{10}\left(\mathrm{PO}_{4}\right)_{6}(\mathrm{OH})_{2}$ & 1,67 \\
Fosfato de cálcio amorfo (ACP) & $\mathrm{Ca}_{3}\left(\mathrm{PO}_{4}\right)_{2} \cdot n \mathrm{H}_{2} \mathrm{O}$ & 1,5 \\
Fosfato tricálcico $\left(\alpha, \alpha^{\prime}, \beta, \gamma\right)(\mathrm{TCP})$ & $\mathrm{Ca}_{3}\left(\mathrm{PO}_{4}\right)_{2}$ & 1,5 \\
Fosfato octacálcico (OCP) & $\mathrm{Ca}_{8} \mathrm{H}_{2}\left(\mathrm{PO}_{4}\right)_{6} \cdot 5 \mathrm{H}_{2} \mathrm{O}$ & 1,33 \\
Mono-hidrogênio fosfato de cálcio di-hidratado & $\mathrm{CaHPO}_{4} \cdot 2 \mathrm{H}_{2} \mathrm{O}$ & 1,0 \\
(DCPD) & & \\
Mono-hidrogênio fosfato de cálcio (DCP) & $\mathrm{CaHPO}_{4}$ & 1,0 \\
Pirofosfato de cálcio (CPP) & $\mathrm{Ca}_{2} \mathrm{P}_{2} \mathrm{O}_{7}$ & 1,0 \\
Pirofosfato de cálcio di-hidratado (CPPD) & $\mathrm{Ca}_{2} \mathrm{P}_{2} \mathrm{O}_{7} \cdot 2 \mathrm{H}_{2} \mathrm{O}$ & 1,0 \\
Fosfato heptacálcico (HCP) & $\mathrm{Ca}_{7}\left(\mathrm{P}_{5} \mathrm{O}_{16}\right)_{2}$ & 0,7 \\
Di-hidrogênio fosfato tetracálcico (TDHP) & $\mathrm{Ca}_{4} \mathrm{H}_{2} \mathrm{P}_{6} \mathrm{O}_{20}$ & 0,67 \\
Fosfato monocálcico mono-hidratado (MCPM) & $\mathrm{Ca}_{2}\left(\mathrm{H}_{2} \mathrm{PO}_{4}\right)_{2} \cdot \mathrm{H}_{20}$ & 0,5 \\
Metafosfato de cálcio $(\alpha, \beta, \gamma)(\mathrm{CMP})$ & $\mathrm{Ca}_{2}\left(\mathrm{PO}_{3}\right)_{2}$ & 0,5 \\
\hline
\end{tabular}

Estes fosfatos de cálcio podem ser sintetizados por precipitação a partir de soluções contendo íons $\mathrm{Ca}^{2+}$ e $\mathrm{PO}_{4}^{3-}$. Os compostos que apresentam o grupo $\mathrm{H}_{2} \mathrm{PO}_{4}^{-}$somente são obtidos em meio ácido, enquanto que os que apresentam os grupos $\mathrm{HPO}_{4}{ }^{2-} \mathrm{e} \mathrm{PO}_{4}^{3-}$ podem ser obtidos sob condições ácidas ou alcalinas. ${ }^{9}$

Uma das propriedades mais importantes dos fosfatos de cálcio, a qual é explorada nas diversas aplicações e que pode predizer seu comportamento in vivo, é a solubilidade em água. De forma geral, quanto maior a razão $\mathrm{Ca} / \mathrm{P}$, menor será a solubilidade. Observando-se as isotermas de solubilidade de sete fosfatos de cálcio, Figura 3, notase a inclinação negativa nas regiões neutras e ácidas do diagrama de fases. Isso reflete o fato de que todos os compostos são mais solúveis conforme o $\mathrm{pH}$ diminui. Na região alcalina, a concentração de cálcio aumenta com o aumento do $\mathrm{pH} .{ }^{10}$ Dessa forma, em $\mathrm{pH}$ fisiológico, a solubilidade dos fosfatos de cálcio e, consequentemente, sua degradação in vivo, é dada pela seguinte ordem: $\mathrm{MCPM}>\alpha$-TCP $>$ DCPD $>$ DCP $>$ OCP $>\beta$-TCP $>$ HÁ

\section{Fosfatos de cálcio de interesse biológico}

\section{Hidroxiapatita $(H A)$}

A HA está presente em ossos e dentes de todos os vertebrados, representando $5 \%$ do peso total de um indivíduo adulto. Representa $55 \%$ da composição de ossos, $96 \%$ da composição do esmalte dentário e $70 \%$ da dentina.

Apresenta fórmula química $\mathrm{Ca}_{5}\left(\mathrm{PO}_{4}\right)_{3} \mathrm{OH}$, podendo ser escrita também como $\mathrm{Ca}_{10}\left(\mathrm{PO}_{4}\right)_{6}(\mathrm{OH})_{2}$, mostrando que há 2 unidades de 


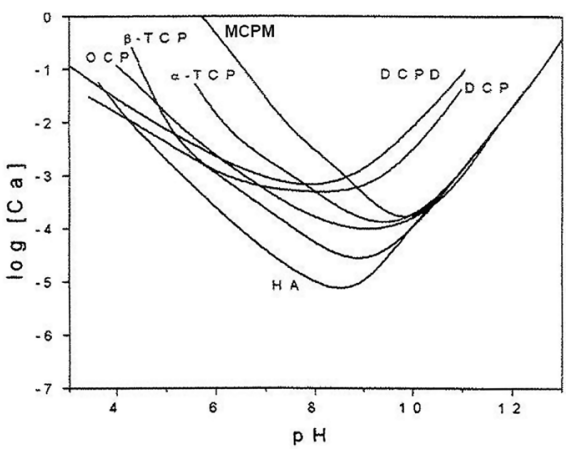

Figura 3. Diagrama de solubilidade para o sistema ternário $\mathrm{Ca}(\mathrm{OH})_{2}-\mathrm{H}_{3} \mathrm{PO}_{4}$ $\mathrm{H}_{2} \mathrm{O}$ a $37^{\circ} \mathrm{C}$ : isoterma de solubilidade mostrando log[Ca] e pH de soluções em equilíbrio com vários sais

fórmula na célula unitária. Cristaliza-se no sistema hexagonal com grupo espacial $\mathrm{P}_{3 / \mathrm{m}}$, onde $\mathrm{P}$ indica que é um sistema hexagonal primitivo, ou seja, $\mathrm{a}=\mathrm{b}=9,43 \AA, \mathrm{c}=6,88 \AA, \alpha=\beta=90^{\circ} \mathrm{e} \quad \gamma=60^{\circ}$. Os átomos de cálcio estão localizados em sítios não equivalentes, sendo 4 no sítio I $\left(\mathrm{Ca}_{1}\right)$ e 6 no sítio II $\left(\mathrm{Ca}_{2}\right)$, e os íons $\mathrm{OH}^{-}$ocupam os denominados sítios canais, Figura $4 .{ }^{11}$

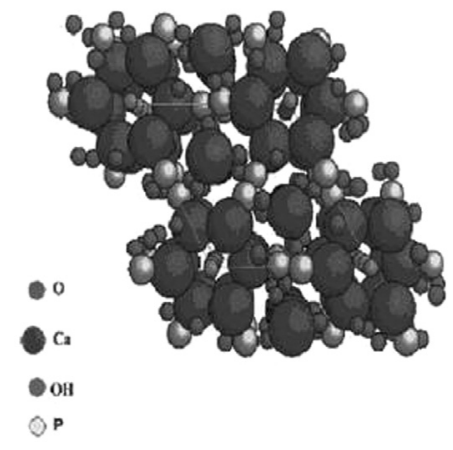

Figura 4. Representações esquemáticas da estrutura cristalina da HA

A estrutura cristalina da HA lhe confere uma de suas mais importantes propriedades, a facilidade de substituições catiônicas e aniônicas, sendo referida como capaz de incorporar metade dos elementos da tabela periódica em sua estrutura. Íons $\mathrm{Ca}^{2+}$ podem ser substituídos por um grande número de cátions metálicos mono e divalentes, tais como $\mathrm{K}^{+}, \mathrm{Na}^{+}, \mathrm{Mg}^{2+}, \mathrm{Mn}^{2+}, \mathrm{Ni}^{2+}, \mathrm{Co}^{2+}, \mathrm{Cu}^{2+}, \mathrm{Zn}^{2+}$, $\mathrm{Sr}^{2+}, \mathrm{Ba}^{2+}, \mathrm{Pb}^{2+}, \mathrm{Cd}^{2+}, \mathrm{Fe}^{2+}$, e íons trivalentes de elementos terra rara. A diferença de valência causada por qualquer substituição requer uma redução na carga aniônica para manter o balanço de carga. Íons $\mathrm{PO}_{4}^{3-}$ podem ser substituídos por íons $\mathrm{AsO}_{4}^{3-}, \mathrm{SO}_{4}^{2-}, \mathrm{CO}_{3}^{2-}, \mathrm{SiO}_{4}^{4-}$, $\mathrm{VO}_{4}^{3-}$ e os íons $\mathrm{OH}^{-}$por íons $\mathrm{CO}_{3}^{2-}, \mathrm{F}^{-}, \mathrm{Cl}^{-}$. Todas as substituições podem alterar a cristalinidade, os parâmetros de rede, as dimensões dos cristais, a textura superficial, a estabilidade e a solubilidade da HA que, por sua vez, alteram a degradação e o comportamento in vivo. $\mathrm{O}$ íon $\mathrm{CO}_{3}{ }^{2-}$ pode fazer tanto substituições no sítio do $\mathrm{OH}-$, originando a denominada HA carbonatada do tipo A, quanto no sítio do $\mathrm{PO}_{4}^{3-}$, originando HA carbonatada do tipo B. Para estas substituições ocorrem efeitos opostos nos parâmetros de rede: substituição do tipo A causa expansão no eixo a e contração no eixo c, enquanto que a substituição do tipo B causa contração no eixo a e expansão no eixo c. Além disso, a substituição do tipo B acarreta também a diminuição do tamanho dos cristais e da cristalinidade. As substituições catiônicas por $\mathrm{Sr}^{2+} \mathrm{e} \mathrm{Mg}^{2+}$ causam aumento da solubilidade. ${ }^{12}$

Nos organismos vivos, sua facilidade de substituições catiônicas e aniônicas faz com que a HA atue como reserva de cálcio e fósforo e um sistema regulador de diferentes íons nos líquidos corporais por meio de sua liberação ou armazenamento. A Tabela 4 apresenta a composição inorgânica de ossos e dentes. Essa característica é também responsável pela crescente utilização da HA na área ambiental para o tratamento de solos e águas contaminados e dejetos industriais. ${ }^{5}$

Tabela 4. Composição inorgânica de ossos e dentes

\begin{tabular}{cccc}
\hline & \multicolumn{3}{c}{ Dente } \\
Elementos & Osso (\%) & Dentina (\%) & Esmalte (\%) \\
\hline $\mathrm{Ca}$ & 34 & 35 & 37 \\
$\mathrm{P}$ & 15 & 16 & 17 \\
$\mathrm{Mg}$ & 0,5 & 1 & 0,4 \\
$\mathrm{Na}$ & 0,8 & 0,4 & 0,6 \\
$\mathrm{~K}$ & 0,2 & 0,1 & 0,2 \\
$\mathrm{C}$ & 1,5 & 1,1 & 0,8 \\
$\mathrm{Cl}$ & 0,2 & Traços & 0,3 \\
$\mathrm{~F}$ & 0,08 & 0,03 & 0,01 \\
\hline
\end{tabular}

Outra propriedade da HA é a adsorção de proteínas em sua superfície. Proteínas com ponto isoelétrico maior que 8 são adsorvidas na superfície da $\mathrm{HA}$ devido à interação elétrica entre os grupos $\mathrm{PO}_{4}$ da HA com grupos $\mathrm{NH}_{4}$ da proteína. No caso de proteínas ácidas a adsorção ocorre pela formação do complexo HA-Ca ${ }^{2+\ldots}$-OOCproteína. Esta propriedade é responsável pela utilização da HA como adsorvente em cromatografia líquida de alta performance (HPLC) para a separação de proteínas e ácidos nucleicos. ${ }^{12}$

$\mathrm{Na}$ área de biomateriais, a HA apresenta-se como material de referência, pois, além da sua similaridade com a parte mineral de ossos e dentes, exibe excelentes biocompatibilidade, osteocondutividade e bioatividade, permite a proliferação de células ósseas (fibroblastos e osteoblastos) as quais não a distinguem da superfície do osso e hidrofilicidade, permitindo o molhamento de sua superfície por líquidos corporais. ${ }^{12}$

Apesar de todas as vantagens exibidas pela HA seu uso clínico é limitado devido à sua lenta biodegradação. Estudos efetuados por longos períodos de tempo têm mostrado que a HA começa a ser reabsorvida gradualmente após 4 a 5 anos de implantação. A reabsorção é uma característica desejada para biomateriais nos quais o processo de degradação é concomitante com a reposição do osso em formação.

\section{Fosfato de cálcio amorfo (ACP)}

Embora não pareça existir em quantidade detectável nos tecidos duros dos vertebrados, o ACP tem sido encontrado em sistemas biológicos como composição de cálculos dentários e urinários. Apresenta interesse como biomaterial, pois ocorre como uma fase intermediária durante a formação de fosfatos de cálcio no meio biológico e em sistemas aquosos. ${ }^{13}$

Apresenta fórmula química $\mathrm{Ca}_{3}\left(\mathrm{PO}_{4}\right)_{2} \cdot n \mathrm{H}_{2} \mathrm{O}$, com n variando de 3 a 4,5. Corresponde em composição à HA deficiente em cálcio de composição $\mathrm{Ca}_{9} \mathrm{H}_{2}\left(\mathrm{PO}_{4}\right)_{6} \cdot \mathrm{nH}_{2} \mathrm{O}$.

Análises por microscopia eletrônica de transmissão mostram que o ACP é formado por aglomerados de pequenas partículas esféricas amorfas com diâmetros de 20 a $120 \mathrm{~nm}$. Há a possibilidade que o ACP apresente uma estrutura semelhante à da HA, mas como os cristais são muito pequenos esta fase aparece como amorfa. Alguns autores descrevem a ocorrência de dois tipos de ACP, denominados de ACP1 e ACP2, os quais apresentam a mesma composição, diferindo apenas em morfologia. As morfologias características para estes compostos são, respectivamente, grãos esféricos e morfologia flocular, apresentadas na Figura 5. ${ }^{14}$

Baseado no método de distribuição radial de raios-X, é proposto que o ACP é formado por clusters esféricos de aproximadamente 0,95 nm de diâmetro, de composição $\mathrm{Ca}_{9}\left(\mathrm{PO}_{4}\right)_{6}$, denominados clusters de Posner, com moléculas de água nos interstícios, Figura 6. 


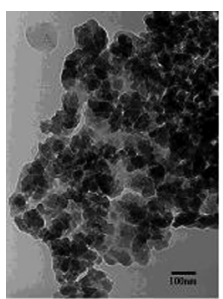

(a)

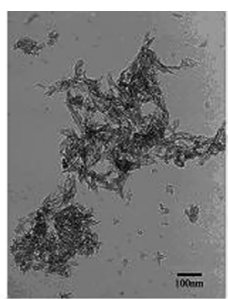

(b)
Figura 5. Morfologias características do ACP1(a) e ACP2(b)

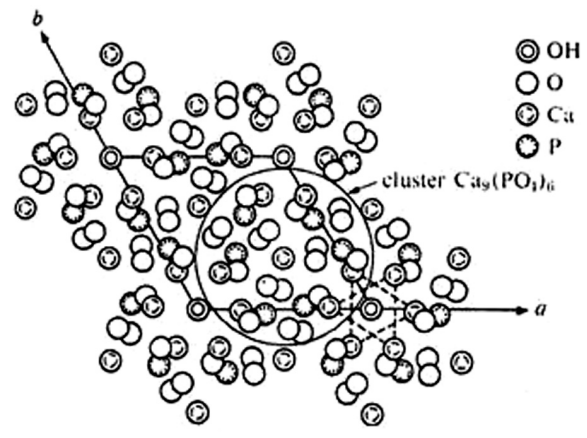

Figura 6. Distribuição dos clusters de ACP

As principais propriedades apresentadas pelo ACP são:

- possibilidade de substituições catiônicas e aniônicas: apresenta característica semelhante à HA, porém com menor número de possibilidades de substituições, incluindo apenas os íons $\mathrm{Mg}^{2+}$ como substituintes do $\mathrm{Ca}^{2+}$ e $\mathrm{CO}_{3}^{2-}$ e $\mathrm{F}^{-}$como substituintes do $\mathrm{PO}_{4}^{3-}$;

- habilidade de transformação a outros fosfatos de cálcio: reconhece-se que o ACP ocorra como uma fase metaestável nos estágios iniciais da formação de fosfatos de cálcio a partir de soluções aquosas supersaturadas, em pH neutro ou alcalino e, também, durante a mineralização dos tecidos vivos. Pode converter-se diretamente a HA ou tendo como fases intermediárias fosfato octacálcico (OCP) e HA deficiente em cálcio;

- solubilidade: a maior solubilidade do ACP em comparação à HA torna-se uma característica importante para a sua utilização como biomaterial, pois lhe confere maior velocidade de degradação no meio biológico. A velocidade de degradação de um material está fortemente relacionada à osteocondutividade e desempenha papel importante na fixação inicial de implantes com o tecido ósseo. Um

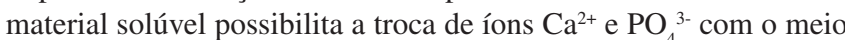
biológico, facilitando o crescimento ósseo.

\section{Fosfato octacálcico $(\mathrm{OCP})$}

Além de ocorrer como fase intermediária durante a formação de ossos e dentes, convertendo-se diretamente à HA, o OCP participa do processo de controle da morfologia dos cristais presentes no tecido ósseo através da sua adsorção na superfície da matriz proteica amelogenina, que é responsável por este processo. ${ }^{15}$

Apresenta fórmula química $\mathrm{Ca}_{8}\left(\mathrm{HPO}_{4}\right)_{2}\left(\mathrm{PO}_{4}\right)_{4} \cdot 5 \mathrm{H}_{2} \mathrm{O}$ e estrutura cristalina pertencente ao sistema triclínico ( $\mathrm{P} \overline{1})$ com parâmetros de rede $\mathrm{a}=19,71 \AA, \mathrm{b}=9,53 \AA$ e c $=6,83 \AA$ e $\alpha=9,014^{\circ}, \beta=92,52^{\circ}$ e $\gamma=108,67^{\circ}$. Consiste de um arranjo alternado entre camadas com estrutura semelhante à da $\mathrm{HA}$ de composição $4\left[\mathrm{Ca}_{3}\left(\mathrm{PO}_{4}\right)_{2} .0,5 \mathrm{H}_{2} \mathrm{O}\right]$ e camadas hidratadas de composição $4\left[\mathrm{CaHPO}_{4} \cdot 2 \mathrm{H}_{2} \mathrm{O}\right]$, apresentado na Figura 7.,16

Como pode ser observado na Figura 7, a formação do OCP se dá numa região intermediária entre $\mathrm{CaHPO}_{4} \cdot 2 \mathrm{H}_{2} \mathrm{O}$ e HA, explicando a composição de suas camadas e a similaridade de suas propriedades com a HA.

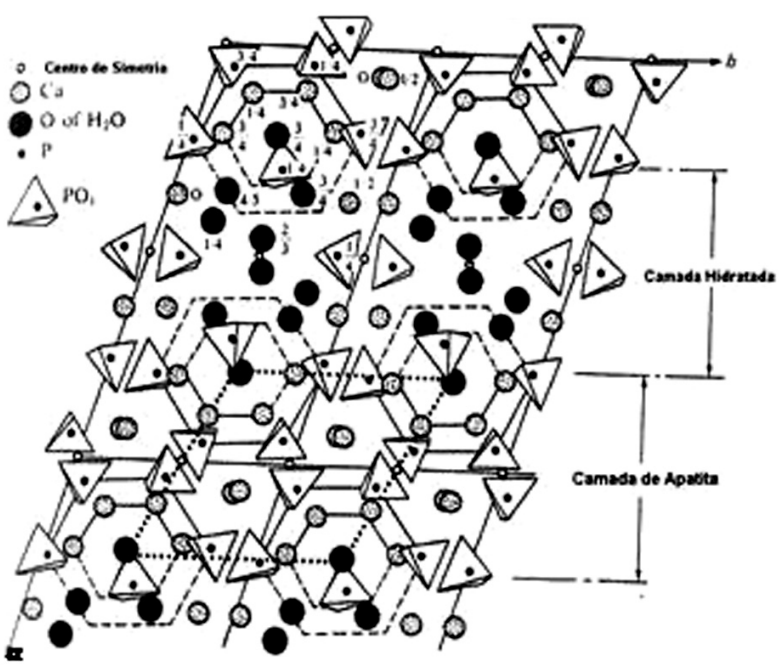

Figura 7. Estrutura cristalina do $O C P$

As principais propriedades do OCP são: $:^{17,18}$

- possibilidade de substituições catiônicas e aniônicas: a estrutura do OCP permite a incorporação de íons $\mathrm{Cd}^{2+}, \mathrm{Cu}^{2+}$ e F-, este último levando à formação de fluorapatita $\left[\mathrm{Ca}_{5}\left(\mathrm{PO}_{4}\right)_{3} \mathrm{~F}_{2}\right]$. A capacidade de adsorção destes íons pelo OCP é maior que a da HA e menor que do composto $\mathrm{CaHPO}_{4} \cdot 2 \mathrm{H}_{2} \mathrm{O}$;

- adsorção de proteínas: o OCP adsorve proteínas em sua superfície tão bem quanto a HA;

- conversão à HA: o OCP é uma fase metaestável e sua transformação a HA é termodinamicamente favorável, sendo espontânea e irreversível. Esta transformação ocorre através da hidrólise do OCP, acompanhada pelo consumo de íons $\mathrm{Ca}^{2+}$ do fluido biológico, segundo a reação:

$\mathrm{Ca}_{8}\left(\mathrm{HPO}_{4}\right)_{2}\left(\mathrm{PO}_{4}\right)_{4} \cdot 5 \mathrm{H}_{2} \mathrm{O}+2 \mathrm{Ca}^{2+}+2 \mathrm{OH}^{-}+2 \mathrm{H}_{2} \mathrm{O} \rightarrow$ $\mathrm{Ca}_{10}\left(\mathrm{PO}_{4}\right)_{6}(\mathrm{OH})_{2}+5 \mathrm{H}_{2} \mathrm{O}+2 \mathrm{H}_{3} \mathrm{O}^{+}$

A presença de íons $\mathrm{Mg}^{2+}$ na solução numa razão $\mathrm{Mg} / \mathrm{Ca}$ superior a 0,02 inibe a transformação do $\mathrm{OCP}$, devido à incorporação preferencial do $\mathrm{Mg}^{2+}$ na estrutura de fosfatos de cálcio;

- proliferação celular e osteocondutividade: a utilização de OCP como biomaterial vem crescendo acentuadamente, pois estudos revelam que este composto apresenta as propriedades de proliferação celular e osteocondutividade mais acentuadas que da HA, devido à sua maior velocidade de reabsorção em comparação à HA. A reabsorção do OCP estimula a regeneração óssea logo nos estágios iniciais de aposição óssea, sendo seguida pela formação de novo tecido ósseo. Dessa forma, o OCP é considerado um substituto ósseo mais adequado que a HA em aplicações onde se requer rápida formação óssea.

Dekker et al. ${ }^{17}$ analisaram o comportamento in vitro, mediante cultura de células da medula óssea, e in vivo, mediante implantação em ratos, de amostras de Ti recobertas com HA carbonatada e OCP. Os resultados mostraram que a proliferação e adesão celular foram maiores nas amostras recobertas por OCP. Além disso, o recobrimento de OCP ocasionou a formação de maior volume de tecido ósseo na superfície do Ti, sendo este osso mais organizado que o formado sobre o recobrimento de HA carbonatada.

Estudo semelhante foi realizado por Imaizumi et al. ${ }^{18}$ confirmando os resultados de Dekker et al. ${ }^{17}$ Os autores atribuíram o melhor comportamento do OCP à sua maior velocidade de reabsorção, que é seguida pela formação de novo tecido ósseo. Esses resultados indicam que o OCP é um substituto ósseo mais adequado que a HA em aplicações onde se requer rápida formação óssea. 
Fosfato tricálcico (TCP)

Ocorre em várias calcificações patológicas, como cálculos dentários e urinários e é o principal constituinte de cáries dentárias.

Pode ocorrer em 4 formas alotrópicas, onde as temperaturas de transição e sequência de ocorrência são:

$\beta-\mathrm{TCP} \stackrel{1120-1180^{\circ} \mathrm{C}}{\longrightarrow} \alpha-\mathrm{TCP} \stackrel{1430-1470^{\circ} \mathrm{C}}{\longrightarrow}-\alpha^{\prime}-\mathrm{TCP}$

a fase $\gamma$-TCP só ocorre em altas pressões. A estrutura cristalina e os parâmetros de rede de cada fase são apresentados na Tabela 5. A estrutura cristalina da fase $\alpha^{\prime}$-TCP não é conhecida devido à dificuldade de preparação.

Tabela 5. Estruturas cristalinas e parâmetros de rede das fases alotrópicas do TCP

\begin{tabular}{lcccc}
\hline & Sistema & $\mathrm{a}(\mathrm{nm})$ & $\mathrm{b}(\mathrm{nm})$ & $\mathrm{c}(\mathrm{nm})$ \\
\hline$\alpha$-TCP & Monoclínico & 1,287 & 2,728 & 1,521 \\
$\beta$-TCP & Romboédrico & 1,043 & 1,043 & 3,737 \\
$\gamma$-TCP & Romboédrico & 0,524 & - & 1,867 \\
\hline
\end{tabular}

As principais propriedades apresentada pelo TCP incluem: $:^{2,5,19,20}$ - possibilidade de substituições catiônicas: a forma alotrópica $\beta$-TCP possibilita que até cerca de $15 \%$ dos íons $\mathrm{Ca}^{2+}$ sejam trocados por $\mathrm{Mg}^{2+}$ sem mudanças significativas em sua estrutura, originando o composto denominado de $\beta$-TCP substituído por magnésio;

- bioatividade e osteocondutividade: as formas alotrópicas $\alpha \mathrm{e}$ $\beta$-TCP exibem a mesma habilidade de osteocondução, porém a fase $\alpha$-TCP apresenta maior bioatividade, sendo este fato atribuído ao arranjo estrutural desta fase que possibilita que maior quantidade de

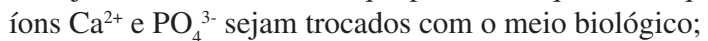

- biodegradação: a utilização do TCP juntamente com a HA tem sido uma alternativa viável para aumentar a velocidade de reabsorção da HA. Nestes casos, a velocidade de dissolução da mistura HA/ TCP é controlada pela quantidade de TCP utilizado. Devido ao seu comportamento biodegradável, o TCP nas formas alotrópicas $\alpha$ e $\beta$ tem se tornado objeto de interesse na área de biomateriais, sendo utilizado na ortopedia e odontologia como material de preenchimento de cavidades e defeitos ósseos e fixação de tecidos moles.

\section{Métodos de obtenção de recobrimentos de fosfatos de cálcio}

Fosfatos de cálcio têm sido utilizados como recobrimentos de implantes ortopédicos e odontológicos para providenciarem um ambiente condutivo para a formação e o crescimento ósseo na superfície destes implantes e promoverem a estabilização do implante a longo e curto prazo. ${ }^{21}$ Os métodos de recobrimento de superfícies com fosfatos de cálcio incluem: plasma spray, sol-gel, eletrólise e biomimético. Todos estes métodos foram desenvolvidos com o objetivo de se obter recobrimento de HA, pois até então o interesse na utilização de outros fosfatos de cálcio ainda não havia sido despertado. ${ }^{22}$

Apesar das qualidades biológicas satisfatórias dos fosfatos de cálcio, por se tratarem de materiais cerâmicos, apresentam baixa resistência à fratura quando submetidos a esforços de tração. As cerâmicas sofrem uma quantidade crítica de deformação elástica e fraturam imediatamente após serem submetidas a esforços de tração, ao contrário dos metais que sofrem um segundo estágio de deformação plástica antes de fraturarem, conforme pode ser observado pelo gráfico de tensão x deformação apresentado na Figura 8. Portanto, a utilização de fosfatos de cálcio como biomateriais é restrita a locais onde ocorram predominantemente esforços de compressão. Por outro lado, metais e polímeros, que apresentam propriedades mecânicas satisfatórias, não exibem comportamento biológico adequado. Uma alternativa desenvolvida para combinar a resistência mecânica de metais e polímeros com as propriedades biológicas dos fosfatos de cálcio é a utilização de recobrimentos da superfície bioinerte com o material bioativo. Neste caso, a capacidade de ligação com o tecido ósseo apresentada pela superfície bioativa é associada às propriedades mecânicas apresentadas pelo substrato. ${ }^{23}$

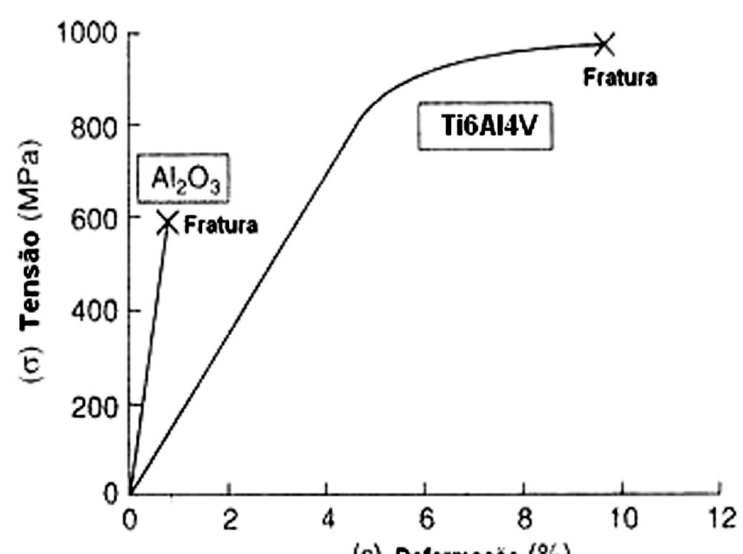

(E) Deformagäo $(\%)$

Figura 8. Curva de tensão x deformação de cerâmicas e metais

\section{Plasma spray ou aspersão térmica}

Este método consiste em colocar o pó do material bioativo em um gás transportador, geralmente argônio, que é ionizado ao passar por um arco elétrico com alta temperatura estabelecido entre dois eletrodos, sendo um ânodo de cobre e um cátodo de tungstênio. O gás alcança temperaturas de até $10.000{ }^{\circ} \mathrm{C}$ dentro do arco e entre 2.000 a $3.000{ }^{\circ} \mathrm{C}$ a $6 \mathrm{~cm}$ do arco. Nestas condições, o pó de fosfato de cálcio é transportado em alta velocidade através do gás, fundindo-se parcialmente e sendo projetado sobre o substrato a ser recoberto, sofrendo resfriamento rápido. $\mathrm{O}$ substrato a ser recoberto pode alcançar até $300{ }^{\circ} \mathrm{C}$. O recobrimento é produzido mediante a deposição de várias camadas. A espessura final do recobrimento é de 40 a $60 \mu \mathrm{m}$.

É o único método utilizado para fins comerciais para recobrir implantes ortopédicos e odontológicos, pois quando da sua criação o equipamento tecnológico usado foi disponibilizado a um preço acessível e os resultados indicaram produtividade adequada. ${ }^{24-26}$

Devido às elevadas temperaturas de processo, este método apresenta as seguintes desvantagens: restrição da utilização somente para substratos metálicos; utilização somente de HA como material de recobrimento, pois os demais fosfatos de cálcio sofreriam decomposição térmica; ligação puramente mecânica entre o recobrimento e o substrato; recobrimentos comportam-se como cerâmica frágil falhando quando submetidos a cargas de tração, devido à diferença entre os coeficientes de expansão térmica do substrato e da HA.

\section{Deposição eletrolítica}

É um método de eletrólise convencional que se baseia na redução catódica da água: $\mathrm{H}_{2} \mathrm{O}+\mathrm{e}^{-} \rightarrow 1 / 2 \mathrm{H}_{2}+\mathrm{OH}^{-}$

Esta reação eletrolítica produz um aumento local do $\mathrm{pH}$ nas imediações do cátodo, sendo este aproveitado para a precipitação de

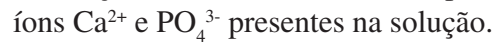

O substrato a ser recoberto atua como cátodo e um eletrodo de platina como ânodo, sendo imersos em uma solução rica em íons $\mathrm{Ca}^{2+} \mathrm{e}$ $\mathrm{PO}_{4}{ }^{3-}$. O pH da solução e a densidade da corrente determinarão a quantidade e a composição do fosfato de cálcio obtidas no recobrimento.

Trata-se de um método que emprega equipamento de baixo custo e conhecimentos científicos e tecnológicos bem estabelecidos, 
porém apresenta como desvantagens permitir o recobrimento apenas de substratos metálicos e as velocidades de formação e adesão do recobrimento são baixas. ${ }^{23}$

\section{Sol-gel ${ }^{24-26}$}

É um método de via úmida que utiliza alcóxidos metálicos ou sais inorgânicos como fonte de cátions e ânions, água como agente de hidrólise e alcoóis como solventes.

A primeira etapa do processo consiste na hidrólise do alcóxido $\left(\mathrm{M}(\mathrm{OR})_{\mathrm{n}}\right)$, gerando um hidróxido metálico $(\mathrm{M}-\mathrm{OH})$, fazendo com que a solução se torne um sol. Em seguida, ocorre a condensação das espécies M-OH, solidificando o sol em um gel. Os géis, após secagem, podem ser os produtos finais ou por calcinação ou sinterização podem se transformar em outros produtos como pós, fibras, monólitos ou recobrimentos cerâmicos.

A utilização do processo sol-gel para a obtenção de recobrimentos de fosfatos de cálcio é bastante recente. Como os alcóxidos de cálcio e fósforo apresentam baixa solubilidade em água, o que levaria à formação de um sol não muito homogêneo, os precursores mais indicados para a obtenção de recobrimentos de fosfatos de cálcio são nitrato de cálcio, ácido fosfórico e fosfato de amônio dibásico. As temperaturas de sinterização e calcinação variam de acordo com a fase de fosfato de cálcio desejada no recobrimento.

Este método apresenta como principais vantagens: controle das características do recobrimento; baixas temperaturas de processo; permite a obtenção de diferentes fosfatos de cálcio; possibilidade de recobrimento de substratos metálicos e também poliméricos; simplicidade do equipamento tecnológico empregado; baixo custo.

Por se tratar de um método com emprego recente na área de biomateriais, a literatura carece de dados quanto à aderência do recobrimento. ${ }^{27-29}$

\section{Método biomimético}

Em 1990, foi desenvolvido por Abe e colaboradores um procedimento que permite recobrir praticamente qualquer substrato com uma camada uniforme de HA similar à biológica com até $15 \mu \mathrm{m}$ de espessura, denominado método biomimético de recobrimento. $\mathrm{O}$ procedimento foi originalmente empregado sobre Ti c.p., ligas de Ti-6Al-4V, aço inoxidável SUS 316, Pt e Cu, além da $\mathrm{Al}_{2} \mathrm{O}_{3}, \mathrm{ZrO}_{2}$, vidro de sílica, polimetacrilato de metila e polietileno; posteriormente, foi aplicado com êxito a poli(etilenotereftalato), poli(etersulfona), poliamida 6, poli(tetrafluoretileno) e poli(alcoolvinílico), sendo que a única limitação aparente é a natureza do substrato que deve ser estável no meio utilizado e não liberar substâncias inibidoras da nucleação da HA. Trata-se de um método de nucleação heterogênea que permite recobrir substratos metálicos, poliméricos e cerâmicos. ${ }^{30-32}$

Mimetiza o processo biológico de formação de ossos e dentes através da utilização de uma solução de composição, $\mathrm{pH}$ e temperatura similares ao plasma sanguíneo denominada simulated body fluid $S B F$. A composição iônica do plasma sanguíneo e da solução SBF é apresentada na Tabela 6 .

Tabela 6. Composição iônica do plasma sanguíneo e da solução $\mathrm{SBF}\left(\mathrm{mmol} \mathrm{dm}^{-3}\right)$

\begin{tabular}{lcccccccc}
\hline & $\mathrm{Na}^{+}$ & $\mathrm{K}^{+}$ & $\mathrm{Mg}^{2+}$ & $\mathrm{Ca}^{2+}$ & $\mathrm{Cl}^{-}$ & $\mathrm{HPO}_{4}^{2-}$ & $\mathrm{SO}_{4}{ }^{2-}$ & $\mathrm{HCO}_{3}^{-}$ \\
\hline Plasma sanguíneo & 142,0 & 5,0 & 1,5 & 2,5 & 103,0 & 1,0 & 0,5 & 27,0 \\
SBF & 142,0 & 5,0 & 1,5 & 2,5 & 147,8 & 1,0 & 0,5 & 4,2 \\
\hline
\end{tabular}

O método inicialmente proposto consistia em colocar em SBF o substrato a ser recoberto juntamente com um vidro bioativo de composição em peso (\%) $\mathrm{MgO} 4,6, \mathrm{CaO} 44,7, \mathrm{SiO}_{2} 34,0, \mathrm{P}_{2} \mathrm{O}_{5} 16,2$ e $\mathrm{CaF}_{2} 0,5$, denominado vidro G. O sistema era mantido a $37^{\circ} \mathrm{C}$ por 7 dias, formando-se uma camada homogênea de $1 \mathrm{~mm}$ de espessura, composta por HA carbonatada de baixa cristalinidade semelhante à HA biológica presente no tecido ósseo. Em seguida, o substrato era colocado em uma solução SBF 1,5 vezes mais concentrada, obtendose um recobrimento com a mesma composição, porém com cerca de $15 \mathrm{~mm}$ de espessura.

O mecanismo proposto para a formação do recobrimento foi: os íons silicatos presentes no vidro $\mathrm{G}$ dissolvem-se e adsorvem-se sobre o substrato na forma de grupos $\mathrm{Si}-\mathrm{OH}$; ocorre a nucleação de HA sobre os íons silicatos adsorvidos; os núcleos de HA crescem às custas da $\mathrm{SBF}$ supersaturada em relação à $\mathrm{HA}$, produzindo-se a primeira camada de recobrimento; a espessura da camada aumenta (até $15 \mu \mathrm{m}$ ) às custas da SBF 1,5 vezes mais concentrada.

Desde a sua primeira formulação, o método biomimético sofreu significantes variações, visando acelerar o processo de deposição e alterar a cristalinidade do recobrimento, incluindo pré-tratamentos do substrato que incluem: ${ }^{33-39}$ substituição da placa de vidro $G$ pela prévia imersão dos substratos em solução de silicato de sódio, levando à formação de grupos $\mathrm{Si}-\mathrm{OH}$ na superfície; para substrato metálicos, substituição da solução de silicato de sódio por tratamento em solução de $\mathrm{NaOH} 5 \mathrm{M}$ seguido por tratamento térmico a $600{ }^{\circ} \mathrm{C}$; para substratos poliméricos de cadeia apolar, prévio tratamento em solução de $\mathrm{H}_{2} \mathrm{O}_{2} 30 \%$, formando grupos polares $\mathrm{C}-\mathrm{OH}$ e $\mathrm{C}=\mathrm{O}$; tratamento de superfícies metálicas por feixe de laser; utilização direta da solução SBF 1,5 vezes mais concentrada; diminuição do período de imersão de 14 para 4 dias.

Outra alteração consistiu na modificação da composição da solução biomimética, realizada por Aparecida, ${ }^{40}$ com o objetivo de possibilitar a obtenção das diferentes fases de apatita de importância biológica como recobrimento, tendo em vista que o método biomimético foi inicialmente desenvolvido com o propósito de se obter no recobrimento a HA. Com o crescente interesse na utilização de outros fosfatos de cálcio como recobrimento, a autora desenvolveu 6 diferentes soluções biomiméticas, as quais foram denominadas de SBF modificadas, possibilitando a obtenção das diferentes fases de apatita de importância biológica e o planejamento da composição do recobrimento de acordo com a solução utilizada.

Este método apresenta como principais vantagens o baixo custo, a utilização de baixas temperaturas de processo $\left(<100{ }^{\circ} \mathrm{C}\right)$, a possibilidade de recobrimento de substratos metálicos, poliméricos e cerâmicos com diferentes formas e tamanhos e é o único método que possibilita a obtenção de todos os fosfatos de cálcio de interesse biológico como recobrimento. Porém, ainda apresenta como desvantagem o longo período de imersão (4 dias) necessário para a obtenção de recobrimento.

\section{CONCLUSÕES}

Durante décadas, devido a sua similaridade com a fase mineral de ossos e dentes, a HA foi a única biocerâmica do sistema dos fosfatos de cálcio empregada como biomaterial para reposição e regeneração óssea. A partir do reconhecimento da limitação de seu uso clínico, devido à sua lenta biodegradação, outros fosfatos de cálcio passaram a despertar interesse na utilização como biomateriais, tais como, ACP, OCP e TCP. A maior solubilidade destas fases de apatita faz com que suas propriedades físico-químicas e biológicas superem as da HA, guiando o cenário atual para a classificação destes materiais como substitutos ósseos mais adequados que a HA em aplicações onde se requer rápida formação óssea.

\section{REFERÊNCIAS}

1. http://anbio.org.br/pdf/2/tr10_biomateriais.pdf, acessada em Janeiro 2009. 
2. Kawachi, E.; Bertran, C. A.; Reis, R. R.; Alves, O. L.;; Quim. Nova 2000, 23, 518.

3. Hanawa, T. Em The bone-biomaterial interface; Davies, J. E., ed.; University of Toronto Press: Toronto, 1991, cap. 2.

4. Vallet-Regi, M. González-Calbet; J. M.; Progress Solid State Chem. 2004, 32, 1 .

5. Campbell, A. A.; Materials Today 2003, 26.

6. Best, S. M.; Porter, A. E.; Thian, E. S.; Hyang, J.; J. Eur. Ceram. Soc. 2008, 28, 1319.

7. Hench, L. L.; Biomaterials 1998, 19, 1419.

8. Aoki, H.; Science and medical applications of hydroxyapatite, JAAS: Tokio, 1991.

9. Kanazawa, T.; Inorganic phosphate materials, Elsevier: Tokio, 1989.

10. Santos, L. A.; Tese de Doutorado, Universidade Estadual de Campinas, Brasil, 2002.

11. Desai, A. Y.; Dissertação de Mestrado, University of Cambridge, Cambridge, 2007.

12. Rey, C.; Combes, C.; Drouet, C.; Sfihi, H.; Barroug, A.; Mater. Sci. Eng., C 2007, 27, 198.

13. Julien, M.; Khairoun, I.; Legeros, R. Z.; Delplace, S.; Pilet, P.; Weiss, P.; Daculsi, G.; Bouler, J. M. Guicheux, J.; Biomaterials 2007, 28, 956.

14. Kim, S.; Ryu, H. S.; Jung, H. S.; Hong, K. S.; Mater. Chem. Phys. 2005, 91, 500 .

15. Suzuki, O.; Kamakura, S.; Katagiri, T.; J. Biomed. Mater. Res., Part B 2006, 77, 201.

16. Elliot, J. C.; Structure and chemistry of the apatites and other calcium orthophosphates, Elseiver: New York, 1984.

17. Dekker, R. J.; de Bruijn, J. D.; Stigter, M.; Barrere, F.; Layrolle, P.; van Blitterswijk, C. A.; Biomaterials 2005, 26, 5231.

18. Imaizumi, H.; Sakurai, M.; Kashimoto, O.; Kikawa, T.; Suzuki, O.; Calcif. Tissue Int. 2006, 78, 45.

19. Kwon, S-H.; Jun, Y. -K.; Hong, S. -H.; Kim, H. -E.; J. Eur. Ceram. Soc. 2003, 23, 1039.

20. Xin, R.; Leng, Y.; Chen, J.; Zhang, Q.; Biomaterials 2005, 26, 6477.

21. Oréfice, R. L.; Pereira, M. M.; Mansur, H. S.; Biomateriais: fundamentos e aplicações, Cultura Médica: Rio de Janeiro, 2006.
22. Rigo, E. C. S.; Oliveira, L. C.; Santos, L. A.; Carrodéguas, R. G.; Revista Brasileira de Engenharia Biomédica 1999, 15, 21.

23. Hench, L. L.; Jones, J. R.; Biomaterials, artificial organs and tissue engineering, CRC Press: Cambridge, 2005.

24. Fischer, G.; Ceram. Bull. 1986, 2, 283.

25. Klein, C. P. T. Em An introduction to bioceramics: advanced series in ceramics; Hench, L. L.; Jones, J. R., eds.; World Scientific: Singapore, 1993, cap. 11.

26. Lacefield, W. R. Em ref. 25, cap. 12.

27. Russell, S. W.; Luptak, K. A.; Suchicital, C. T. A.; Alford, T. L.; Pizziconi, V. B.; J. Am. Cer. Soc. 1996, 79, 837.

28. Breme, J.; Zhou, Y.; Groh, L.; Biomaterials 1995, 16, 239.

29. Pechini, M. P.; US pat. 3,330,697 1967.

30. Vossen, J. L.; Kern, W.; Thin film processes, Academic Press: San Diego, 1990.

31. Tanahashi, M.; Yao, T.; Kokubo, T.; Minoda, M.; Nakamura, T.; Yamamuro, T.; J. Am. Ceram. Soc. 1994, 77, 2805.

32. Abe, Y.; Kokubo, T.; Yamamuro, T.; J. Mater. Sci.: Mat. Med. 1990, 1, 536.

33. Bigi, A.; Boanini, E.; Bracci, B.; Facchini, A.; Panzavolta, S.; Segatti, F.; Sturba, L.; Biomaterials 2005, 26, 4085.

34. Chou, Y. F.; Chiou, W. A.; Xu, Y.; Dunn, J. C. Y.; Wu, B. M.; Biomaterials 2004, 25, 5323.

35. Barrere, F.; Blitterswijk, C. A. V.; Groot, K.; Layrolle, P.; Biomaterials 2002, 23, 1921.

36. Barrere, F.; Blitterswijk, C. A. V.; Groot, K.; Layrolle, P.; Biomaterials 2002, 23, 2211.

37. Barrere, F.; Layrolle, P.; Blitterswijk, C. A. V.; Groot, K.; Bone 1999, $25,107 \mathrm{~S}$.

38. Maeyer, E. A. P.; Verbeeck, R. M. H.; Pieters, I. Y.;; J. Cryst. Growth 1996, 169, 539

39. Aparecida, A. H.; Fook, M. V. L.; Guastaldi, A. C.; J. Mater. Sci.: Mater. Med. 2009, 20, 1215

40. Aparecida, A. H.; Dissertação de Mestrado, Universidade Estadual Paulista, Brasil, 2006. 